\title{
Characterisation of a small electrode HPGe detector
}

C. Unsworth, A.J. Boston, H.C. Boston, L.J. HarknessBrennan, D.S. Judson, P.J. Nolan, O.S. Thomas, J.P. Wright, A.S. Adekola, J. Colaresi, W.F. Mueller, J. Simpson

\section{Published version information}

Citation: C Unsworth et al. "Characterisation of a small electrode HPGe detector." Nuclear Instruments and Methods in Physics Research Section A: Accelerators, Spectrometers, Detectors and Associated Equipment, vol. 927 (2019): 293-300.

DOI: $\underline{10.1016 / j . n i m a .2019 .02 .043}$

(C)2019. This manuscript version is made available under the CC-BY-NC-ND 4.0 Licence.

This version is made available in accordance with publisher policies. Please cite only the published version using the reference above. This is the citation assigned by the publisher at the time of issuing the AAM/APV. Please check the publisher's website for any updates. 


\section{Accepted Manuscript}

Characterisation of a small electrode HPGe detector

C. Unsworth, A.J. Boston, H.C. Boston, L.J. Harkness-Brennan, D.S. Judson, P.J. Nolan, O.S. Thomas, J.P. Wright, A.S. Adekola, J. Colaresi, W.F. Mueller, J. Simpson

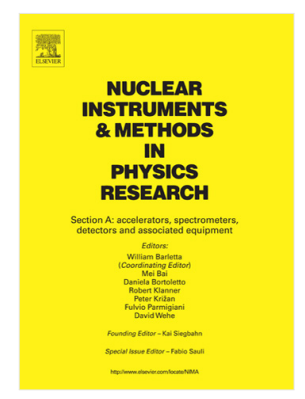

PII: $\quad$ S0168-9002(19)30231-1

DOI: $\quad$ https://doi.org/10.1016/j.nima.2019.02.043

Reference: NIMA 61916

To appear in: Nuclear Inst. and Methods in Physics Research, A

Received date : 25 November 2018

Revised date : 15 February 2019

Accepted date : 16 February 2019

Please cite this article as: C. Unsworth, A.J. Boston, H.C. Boston et al., Characterisation of a small electrode HPGe detector, Nuclear Inst. and Methods in Physics Research, A (2019),

https://doi.org/10.1016/j.nima.2019.02.043

This is a PDF file of an unedited manuscript that has been accepted for publication. As a service to our customers we are providing this early version of the manuscript. The manuscript will undergo copyediting, typesetting, and review of the resulting proof before it is published in its final form. Please note that during the production process errors may be discovered which could affect the content, and all legal disclaimers that apply to the journal pertain. 


\title{
Characterisation of a Small Electrode HPG Desictor \\ C. Unsworth, A.J. Boston, H.C. Boston, L.J. Harkness-B. ^nn ^, D.S. Judson, P.J. Nolan, O.S. Thomas, J.P. Wright. \\ Oliver Lodge Laboratory, University of Liverpool, Live pool, L6. 7ZE, UK
}

A.S. Adekola, J. Colaresi, W.F ־ ruelı,

Mirion Technologies Canberra, 800 Research Parkwa ^eride, CT, 06450, USA

\section{J. Simpson}

STFC Daresbury Laboratory, Daresbury, "rrringtc ı, WA4 4AD, UK

\begin{abstract}
Small electrode HPGe detectors 1.' a. ' nverted coaxial geometry are increasingly in use in applications whe bou .igh efficiency and excellent energy resolution are required. The unusual electric field configuration of these detectors results in extremely long narge c llection times compared to planar and coaxial devices. In this work re ha, $r$ aracterised such a detector using gamma-ray coincidence measure nen ${ }^{+} s$ an : optimised an electric field simulation to reproduce the position 1 variav $\mathrm{n}$ of detector response. We show that, alongside accurate crystai geon ${ }^{+r y}$ and applied electric potential, a temperature correction is crv ial o correctly determining appropriate charge carrier mobility parameter $\lambda_{1}$. work will help to guide the future development of HPGE detectors $\mathrm{f} r$ ar plicr tions including radioactive waste assay, radio-isotope dating, and fundame. + 1 nuclear physics.

Key ords: IPGe, SAGe Well, Charge collection, Charge carrier mobility
\end{abstract}




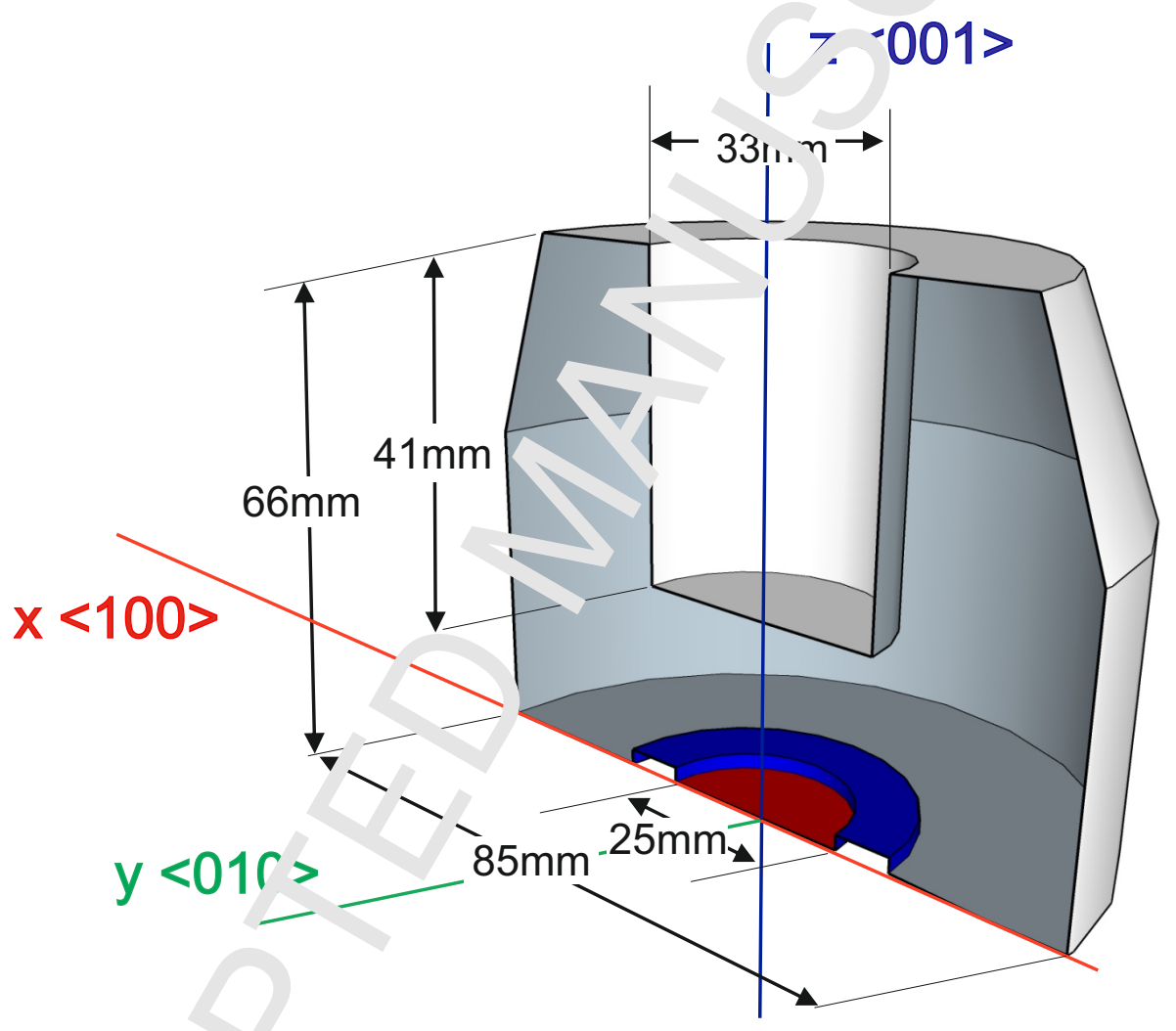

Figure 1: $\{$ her ttic of the SAGe Well HPGe crystal used in this work sliced along the $x$ axis (red). The ${ }_{*}$ nd $z$ axes are shown in green and blue respectively. The $25 \mathrm{~mm}$ diameter $\mathrm{p}+$ electr' te surface $s$ shown on the back face of the crystal in red and the passivated region surro nding it a blue, the $\mathrm{n}+$ electrode covers the remaining surface of the crystal including th - nsiu "ne well. The front face of the crystal is tapered in towards the well in order to liminate regions of very low electric field, which would otherwise lead to significant charge t. npino 


\section{Introduction}

High-resolution gamma-ray spectrometry is used acros a $\mathrm{r}$.ngt of applications. These include a number of fields where both high $m_{\text {ien. }}$ and excellent energy resolution are critical to performance. In appl sations uch as environ5 mental measurements, where sample sizes are ofter ...miteu, a well geometry is often used to maximise efficiency. The Small Anc to Gern anium (SAGe) Well $[1,2,3]$ is a p-type high-purity germanium (HPG, detector manufactured by Mirion Technologies Canberra and designed « have e cellent energy resolution and very high efficiency for gamma-rays emitı ${ }^{\prime}$ by samples placed within the well.

The induced charge signals due , o mma-ray interactions at a range of positions within a SAGe Well dete`tor $h_{1}$ ve been investigated in order to characterise the charge collection behav^ $u_{\Perp}$. Electric field simulations and experimental measurements have bet. iseu or the characterisation with the latter

15 being used to validate and optimise the former. The optimised field simulations can be used to predict $t r\lrcorner$ chara teristics of other similar detectors and aid in the design of future de ices.

In this work we ave user a SAGe Well with a diameter of $85 \mathrm{~mm}$ and a length of $66 \mathrm{~mm}$ ( $\mathrm{ig} .1$ ). - ne crystal has a $33 \mathrm{~mm}$ diameter well bored into the

20 front face to a ciepth $: 11 \mathrm{~mm}$ and a $26 \mathrm{~mm}$ taper which reduces the diameter of the crysta' to $15 \mathrm{~mm}$ at the front. These features help to reduce regions of extremely ' $\mathrm{OW} \wedge^{\prime} \mathrm{l}$, which would otherwise lead to significant charge trapping. A small $\mathrm{o}+$ lect ode of $25 \mathrm{~mm}$ diameter is separated by a passivated region from the $n+1$ ctrode covering the rest of the crystal surface. The operating bias of $-470 \mathrm{a} \mathrm{V}$ was applied to the $\mathrm{p}+$ electrode. Relative to other detector g netrı of similar volume, the small size of the $\mathrm{p}+$ electrode provides reduced apacita ıce and hence electronic noise. This reduced noise helps the detector achieve outstanding energy resolution with FWHM of $0.73 \mathrm{keV}$ at $122 \mathrm{keV}$ and

* Corresponding author 
$1.69 \mathrm{keV}$ at $1332 \mathrm{keV}$. The detector was mechanically cooled by a CP5-p us cryo

30 cooler which allows the device to be operated in any orien ${ }^{+}$tic 1 a fact which facilitated our characterisation measurements.

Points in the detector are described by a Cartesiar coord: ate system with the $x y$ plane coincident with the back face of the detecto. and $\mathrm{t}^{\top} \mathrm{e} e \mathrm{z}$ axis running through the centre of the crystal towards the fro it fa. . The origin is in the

35 centre of the $\mathrm{p}+$ electrode and the $x, y, z$ ay 's run $\mathrm{n}$ - iallel to the $<100>$, $<010>$, and $<001>$ crystal axes respectively (See Fuy 1).

\section{Simulation}

Signal formation in the detector : m brary (ADL) [4] which was adapted for $\mathrm{l}$. is work to incorporate the SAGe Well

40 geometry. The simulation uses a fir. te .'ifference method to solve the electric and weighting fields in the detec ${ }^{\wedge} r$ Deiure tracking holes and electrons through the field using the mobility parameterisation described in [5]. The charge trajectories are then used + , calcu te the signal induced on an electrode using the Shockley-Ramo thr orum

45 ing to the nominal $\varepsilon$ ' $\mathrm{nm}$ tric ind material specification and using the electron and hole mobility parame s described in [8]. Optimisations of the simulation parameters to natch $\omega_{\text {. }}$, experimental signals are described in Sec. 6 .

Fig 2 she s a slice of the calculated electric potential in cylindrical polar coordinate ( $r z$-ith $r$ in the $x y$ plane), the electron and hole trajectories for 50 each of the $\epsilon$ am' le signals we will be considering are also shown (See Sec. 5 and $F^{i}-4 \mathrm{to}_{\boldsymbol{L}^{2}}{ }^{+}$, e equivalent experimental signals). Due to rotational symmetry of $\mathrm{tl}$, detect $\mathrm{r}$ this potential is the same regardless of the angle in the $x y$ plane $a^{+}$hicı vile slice is taken. The unusual field distribution in the volume suroundin the well causes the electrons (dashed blue lines) to follow the potential grauınt towards the closest part of the $\mathrm{n}+$ electrode while the holes approach "ne potential "valley" partway $(r \approx 28 \mathrm{~mm})$ between the outer detector wall and inside of the well. The holes then drift through this valley along the $<001>$ 


\begin{tabular}{|c|c|c|c|}
\hline Position & $x(\mathrm{~mm})$ & $y(\mathrm{~mm})$ & $z(\mathrm{~mm})$ \\
\hline $\mathrm{R} 1$ & -9.5 & 0.5 & 13.5 \\
\hline $\mathrm{R} 2$ & -14.5 & 0.5 & 13.5 \\
\hline R3 / D1 & -27.5 & 0.5 & 13, \\
\hline $\mathrm{R} 4$ & -36.5 & 0.5 & 13.5 \\
\hline D2 & -27.5 & 0.5 & $30 \mathrm{~J}$ \\
\hline D3 & -27.5 & 0.5 & 46. \\
\hline D4 & -27.5 & 0.5 & 620 \\
\hline
\end{tabular}

Table 1: Coordinates in the detector frame of $\ldots$-itions R1 - R4 and D1 - D4

crystal axis with the trajectories fro a ach pusition converging onto a single path as they approach the $\mathrm{p}+$ electroa Holes produced by interactions anywhere in the region surrounding the $w_{c} "$ which represents the majority of the detector volume, follow a simile var.

Fig. 3 shows the weighting potental for the $\mathrm{p}+$ electrode together with the same charge trajectories ' lown ` $\mathrm{n}$ the electric potential. The weighting potential is close to zero thro'ighw ${ }^{+} \mathrm{m}$, st of the detector volume until it begins to rise quickly in the vicinit the $\mathrm{p}+$ lectrode $(z<20 \mathrm{~mm})$. Together these potentials result in a range 'i sign.' napes depending on the position of interaction in the detector. F,r ilı trative purposes we will consider signals produced due to interactior, in positions R1-4 and D1-4, the coordinates for each of these interaction pu ${ }^{\cdot}+$ ons is shown in Table 1. Note that points R3 and D1 are the same.

The con ' in cion of converging hole trajectories and a weighting potential conc ntratec close to the $\mathrm{p}+$ electrode gives rise to the important features of the sig. 1 - 1 apes from positions D1 to D4 (see Fig. 4). Electrons are collected quickly ver a short distance while holes have a long drift with very little induced 75 sig..., then a significant induced signal as the holes approach the electrode $r$ nich has a fixed shape regardless of initial interaction position.

This behaviour results in charge drift times increasing with distance from the 
electrode in both the radial and $z$ directions. Longer collection imes re seen when the charge has to drift further along the common pat in he $z$ direction, or further in the radial direction before reaching the comme sath.

Considering the signals from the set of interaction r usition R1-R4 (Fig. 4), on a line through the detector radius at a fixed $z$ of $.2 .5 \mathrm{~m} \Omega$. Signals from

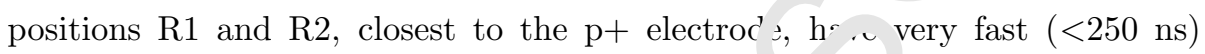
almost linear rising edges. Referring again to the simuls ed electric potential,

${ }_{85}$ Fig. 2, we see that this region of the detector has stral ${ }_{\xi}$ ht electric field lines with a roughly linear change in potential betwe - the,' electrode and the bottom of the well. Electron and hole drift distanma comparable and the charge trajectories for $\mathrm{R} 1$ and $\mathrm{R} 2$ differ only in that $\mathrm{I}^{-} \mathrm{T}$ approaches the $\mathrm{p}+$ electrode at a slightly greater angle, resulting in a s. of , ly greater rise time. Holes still make

90 the dominant contribution to the $i_{1}$. ned ignal, due to the weighting potential for the $\mathrm{p}+$ electrode changing r nre qu rkly close to the electrode, but electrons do play a significant role here unlike ${ }^{1}$ sewhere in the detector.

As the radius of the int ra. see a return to behaviour , ^n in he well walls with electrons playing little part

95 in the induced signal ad t'ie hoies converging onto the same common trajectory before approaching the lect ode.

\section{Experime - l Metnodology}

The Urivers. * of Liverpool detector characterisation system, Fig. 5, consists of : $1 \mathrm{C} \mathrm{Bq}{ }^{137} \mathrm{Cs}$ source mounted inside a lead and tungsten collimation assem $^{1}{ }^{\prime}$. ' $\perp_{1}$, ungsten collimator is $160 \mathrm{~mm}$ long with an outer diameter of $10 \mathrm{n} \mathrm{m}$ and : $1 \mathrm{~mm}$ diameter hole, this sits inside an array of lead blocks. The $x$, osluvi uncertainty produced by the collimator in this measurement varied rom $1.2 \mathrm{~mm}$ diameter at the front of the detector to $2.2 \mathrm{~mm}$ at the back. The entue assembly is mounted on top of a pair of linear stepper motors allowing it $105+\mathrm{s}$ be moved in two dimensions to a precision of $0.1 \mathrm{~mm}$.

This scan table is combined with a fully digital data acquisition system 


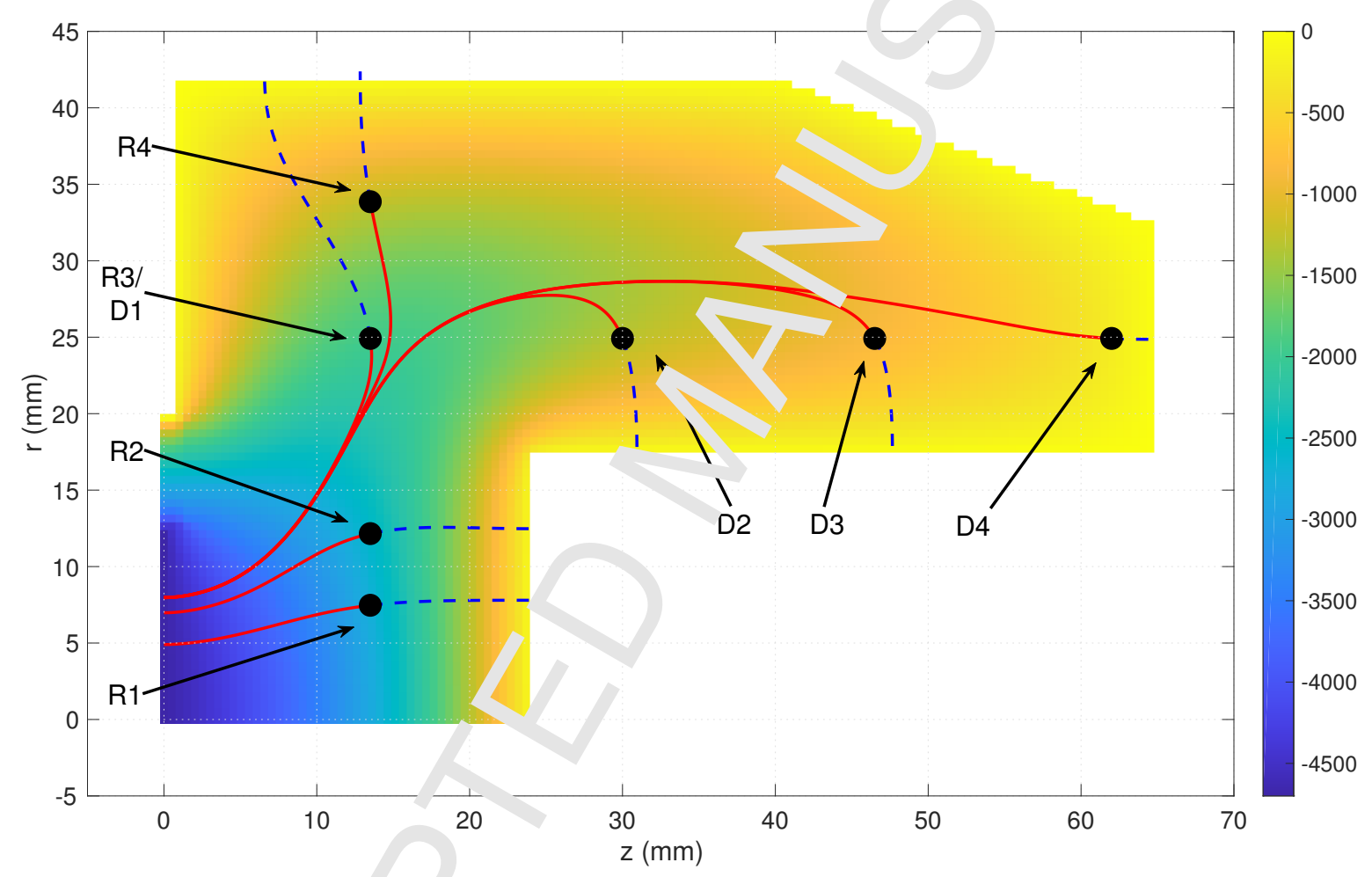

Figure 2: in $r$ slice of the electric potential (Volts) calculated by ADL for the SAGe Well detector, due $>$ ro ttional symmetry of the detector this is the same for a slice taken at any angle $\mathrm{n}$ the $\cdots$ plane. Electron (dashed blue) and hole (red) trajectories are shown for the seven 'xample ositions discussed in the text, the simulated interaction positions are marked v' ... black urcles. 


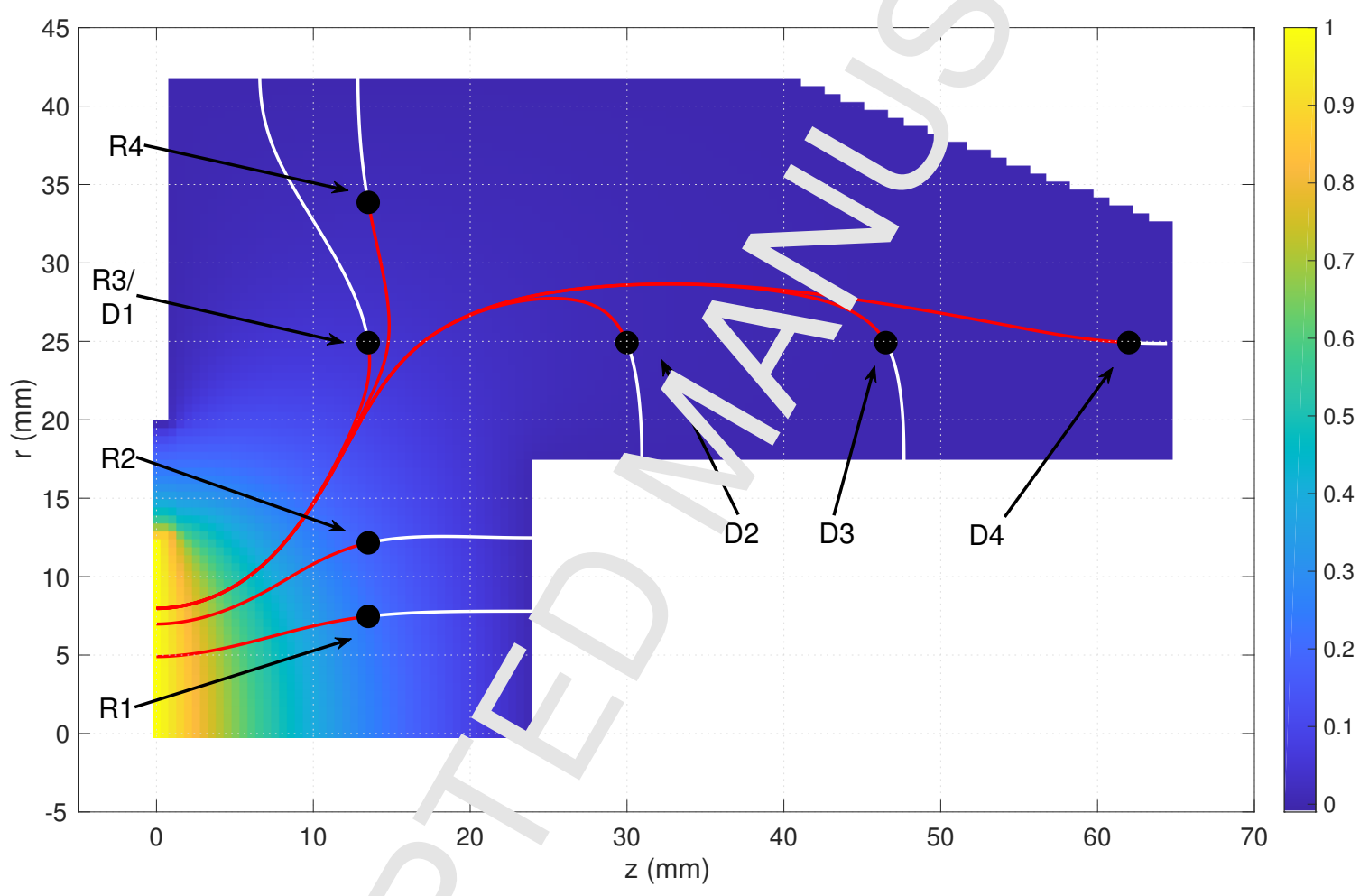

Figure 3: $\mathrm{n} r z$ slice of the weighting potential calculated by ADL for the SAGe Well detector $\mathrm{p}+$ electrodt, tue $\mathrm{o}$ rotational symmetry of the detector this is the same for a slice taken at an angle $>$ the $x y$ plane. Electron (white) and hole (red) trajectories are shown for the seven 'xample nteraction positions discussed in the text, the simulated interaction positions a - . narkeu with black circles. 

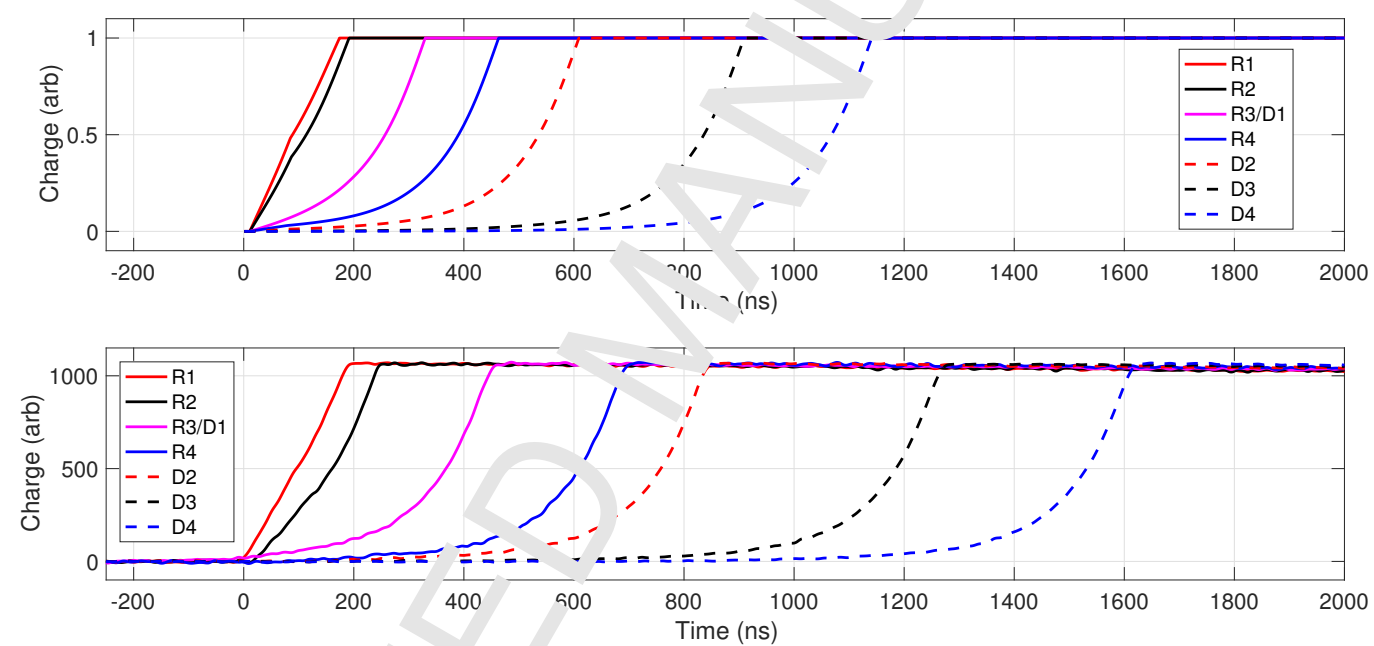

Figure 4: The top anel s. ws simulated signals for selected positions in the detector using the nominal detecto pa rmeters and previously published values for hole and electron mobility, see Sec. 2. I b itom panel shows the experimental mean signals measured during the coincidence can for «. ' same positions, see Sec 3. See Fig. 2 and Fig. 7 for the corresponding interactio loc: ions 


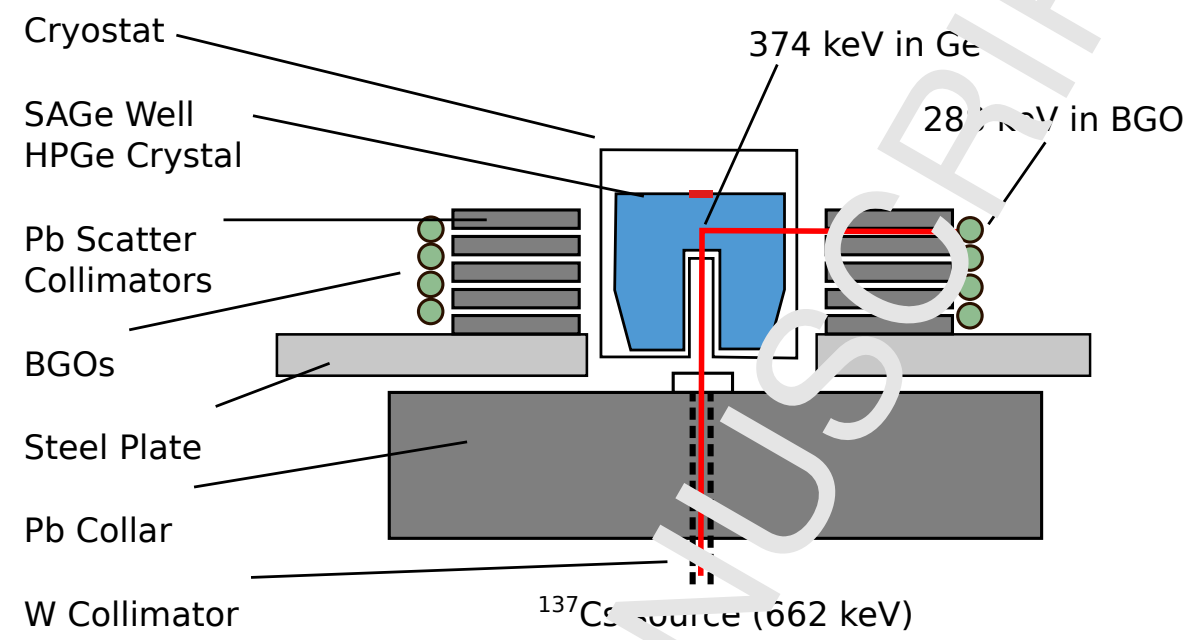

Figure 5: A schematic of the University of $\perp$ ver $\cdots$ - - etector Scanning Table mounted with a SAGe Well detector in coincidence mrde. T. source, primary collimator and lead collar are moved by the stepper motors while th. rt. reinains stationary. The red line indicates an example path of a valid coincidence on oan. na-ray Compton scatter.

using Caen V1724 $100 \mathrm{MH}{ }^{+1}{ }^{1}$ bit digitisers to capture detector charge signals. This system allows the $i$ nsitiona response of a detector to be investigated by interrogating it with + .e heanı of $662 \mathrm{keV}$ gamma rays[9]. The rate of gamma rays coming from the $\sim$ ime or is $\approx 1000$ per second.

The scanning . stem can be operated in two modes, singles and coincidence. In singles scanning mou the collimator is raster scanned across the whole of the detector with che only spatial information coming from the position of the collimator when a interaction occurs. This allows identification of the $x y$ position $\mathrm{O}_{1}{ }^{\mathrm{t}} \mathrm{h} f$ firs' interaction undergone by a gamma ray. This method does

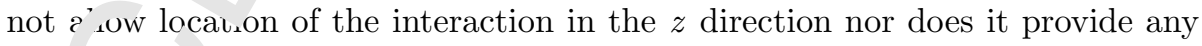
cons, aint $\mathrm{u}$ on the total number of interactions undergone before the full engy is deposited. Despite these limitations the singles scan data are crucial to 'tablis' ing the shape, position, and orientation of the detector crystal in the - me of the scanning system.

The coincidence scan method uses in addition a secondary array of collimating lead blocks with a thickness of $80 \mathrm{~mm}$ and $1.5 \mathrm{~mm}$ gaps created by 
plastic spacers. The gaps are aligned with BGO scintillation \& +ectos; which identify gamma rays that Compton scatter through $90^{\circ}$ at deh iod $z$ positions and subsequently interact in one of the BGO detectors. ' 1 - geometry of the secondary collimators and detectors resulted in a $z$ por tion $u$ certainty from 2 $\mathrm{mm}$ at large radii of interaction to $3 \mathrm{~mm}$ near the cen $\mathrm{a} \mathrm{of} \mathrm{'t'e} \mathrm{detector.} \mathrm{The}$ triggering electronics were configured to read out a 1 eve .u in which interactions occurred in both SAGe Well and BGO detecto within . coincidence window of $2 \mu \mathrm{s}$ to cover the observed range of rise times in $\mathrm{tL}_{\mathrm{L}}$ : detector.

Combining the information from the sec ndaı, ${ }^{3}$, cector with the collimator

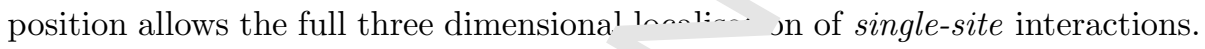
If a number of signals are collected from eac. nosition it is possible to form a mean signal and hence deconvolve the ur deriying detector response from the random electronic noise. The rate $\iota^{r}$ suc coincident interactions varies with position but is typically less the ${ }^{-n}$ ne e ent per minute compared with a random coincidence trigger rate of the order $f 100$ events per minute. This necessitates the use of offline event sel w u techniques to identify the events of interest.

Conservation of enery, and $\mathrm{n}$ smentum ensures that for a fixed gamma-ray energy a scatter thro gh $\left\ulcorner\mathrm{j}^{\circ}\right.$ will deposit a fixed energy in each of the primary and secondary detf sto . in the case of $662 \mathrm{keV}$ gamma rays the values are 374 $\mathrm{keV}$ in the $\mathrm{HPG}$, ad $288 \mathrm{keV}$ in the BGO. Fig. 6 shows a plot of the BGO energy versus - HPGe energy for events measured in time coincidence. The events of int "est can then be selected and the background reduced with gates on both e ergies as shown in the figure. The width of the gates applied depends on both $\mathrm{u}_{-}$- colli nator geometry and the energy resolution of the detectors, in this neasur 'ment our gates were $374 \pm 12 \mathrm{keV}$ in the HPGe and $288 \pm 40$ $\mathrm{keV}$, the ',GO. Prominent lines in the background of Fig. 6 represent the ,62 $\mathrm{ke}^{\mathrm{r}}$ photopeak and $511 \mathrm{keV}$ annihilation photons in the germanium with 1. ndor packground events in the BGO. Further background suppression can be a' $\ldots$. ved by limiting the Ge-BGO time difference to a range of values consistent ith being due to the scattering of a single gamma ray. See Sec. 5 for further discussion of the Ge and BGO time difference. 


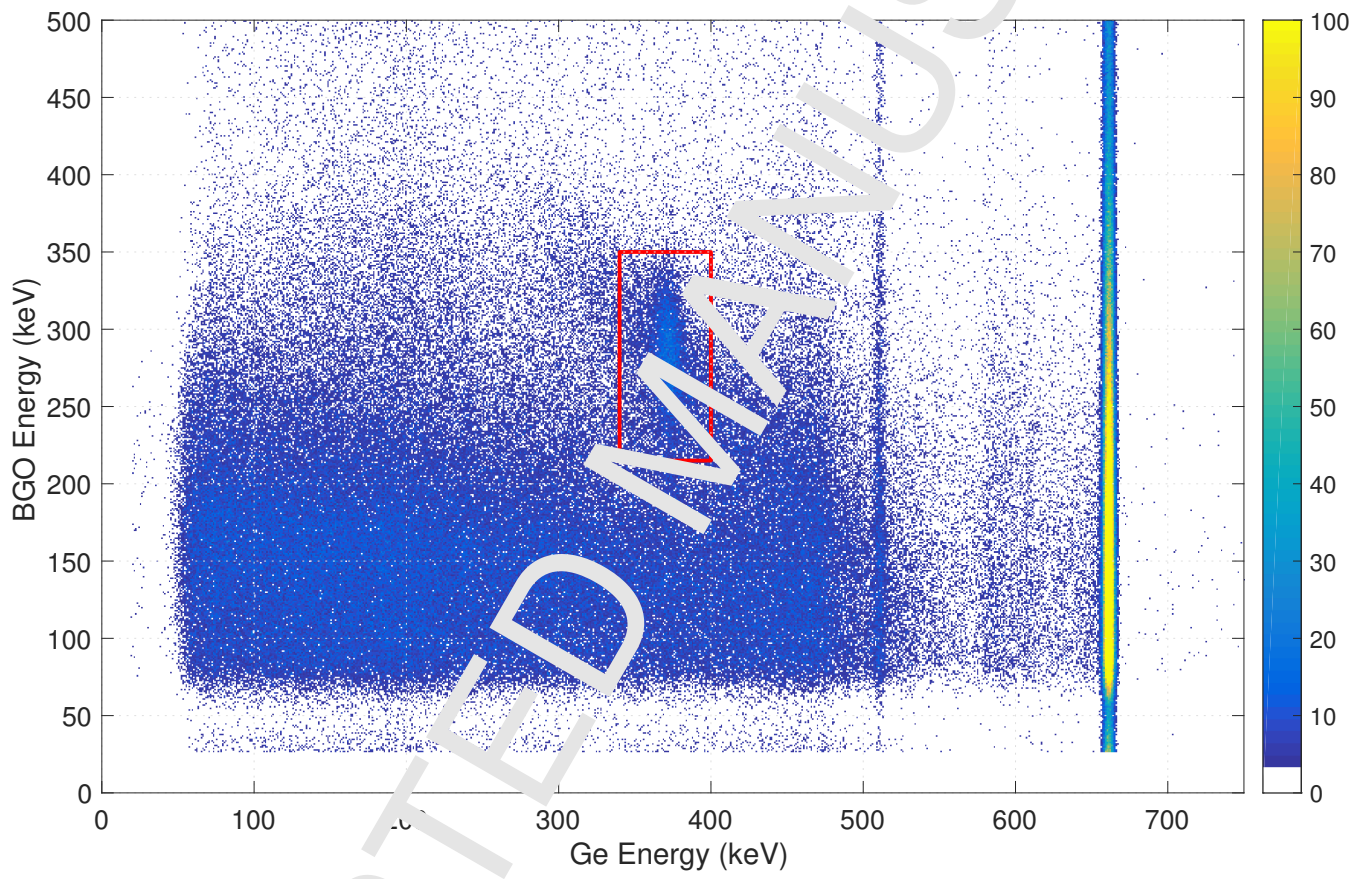

Figure 6: Energy sosited in HPGe and in BGO during the SAGe Well scan. The feature marked by the $d$ box represents Compton scattering through $90^{\circ}$ leaving $374 \mathrm{keV}$ in the germaniun. $\mathrm{d} 28 \mathrm{keV}$ in one of the BGO detectors. Prominent vertical lines represent the $6 f$. $\mathrm{keV}$ nhouspeak and $511 \mathrm{keV}$ annihilation photons in the germanium with random back 'ound ev ats in the BGO. 

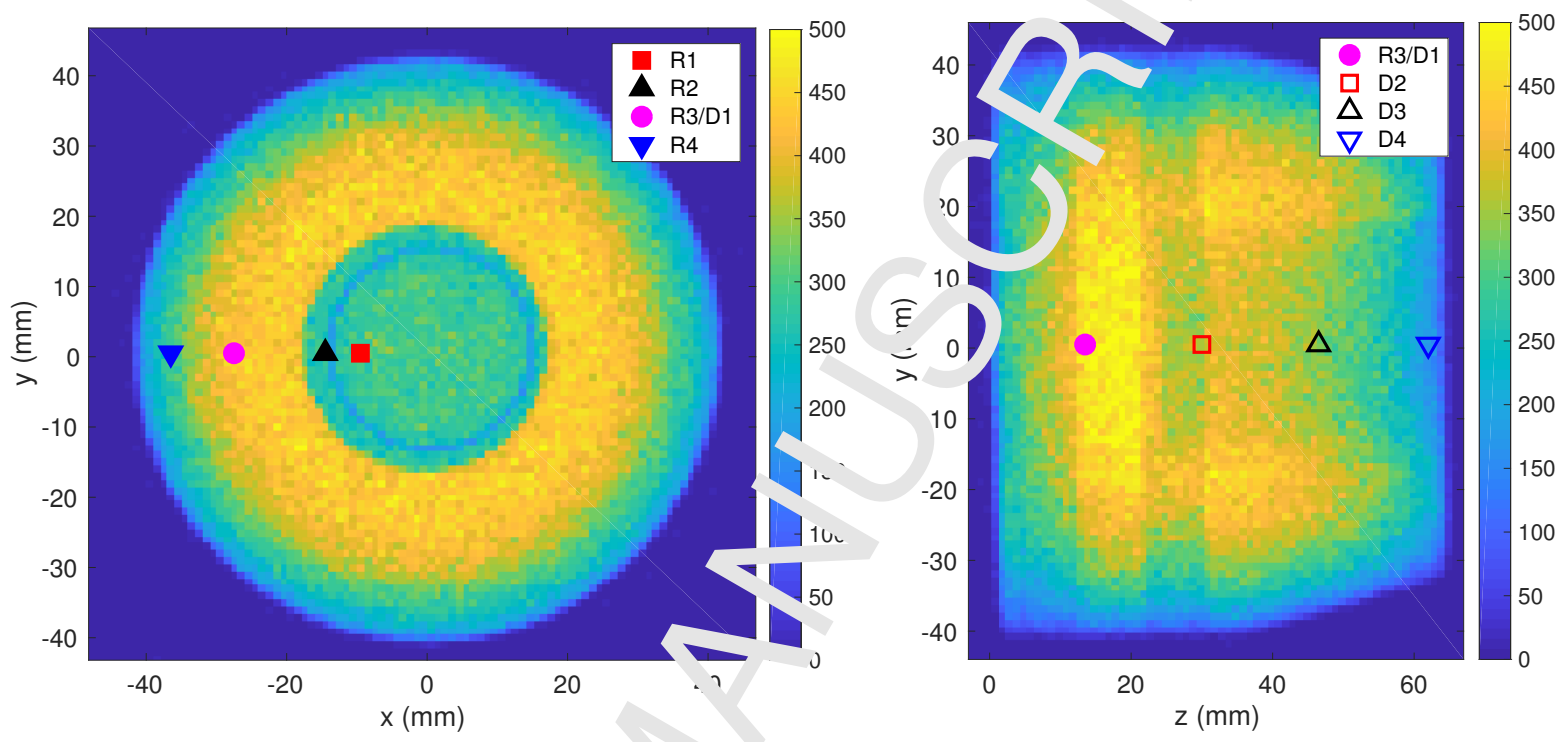

Figure 7: $662 \mathrm{keV}$ photopeak coun as $\mathrm{c}$ : . thion of position for the front (left) and side (right) scans. The coordinates have been $t_{1}$. aslated into the detector frame where the origin is in the centre of the $\mathrm{p}+$ electrr ${ }_{-}$a $r$ the $x, y$, and $z$ axes run parallel to the $\langle 100\rangle,\langle 010\rangle$, and $<001>$ crystal axes resp tively. $\mathrm{E}$ :ample points from the coincidence scan, discussed in Sec. 5 are indicated.

Following the pplı + ic $_{2}$ of initial time and energy gates the signals are 155 interpolated linf arly hetween the measured points at $10 \mathrm{~ns}$ intervals down to 2 ns samples tey are then shifted in time to align the point where they reach $10 \%$ or he f maximum to a fixed sample number and normalised to equal height bf ore in initial mean signal for this position is formed. The final stage of filtering - to ompare each individual signal to this initial mean and measure the ' MS di. ${ }^{r}$ erence between the two, signals with large differences are rejected and $a$ ?nal sean signal is formed from those that remain.

\section{Sir des Scan Results}

Fig. 7 shows the positional variation of $662 \pm 2 \mathrm{keV}$ photopeak counts observed when the SAGe Well detector was scanned with the collimated ${ }^{137} \mathrm{Cs}$ 
source. The left image shows a scan from the front of the ac stor nd the right shows a scan from the side, in both cases the collimat or $n$ ac held at each position for 4 seconds. The most probable way for a $662 \mathrm{~h}$ V photon to leave its full energy in germanium is by first Compton scatte $\mathrm{ng}$ ar. ${ }^{\top}$ then leaving its remaining energy at another location through photoes tric osorption. This results in a reduction in photopeak counts at the deter edges in both scans as the probability of the photon scattering out of the sf ssitive volume before depositing its full energy increases.

The well in the centre of the detector is $\mathrm{v} \cdot \mathrm{ible} \cdot 1$ th scans as a reduction in intensity because there is less sensitive garm.n... material present in the path

175 of the gamma-ray beam. Other regions of $1{ }^{\mathcal{H}}{ }^{1} 1 \mathrm{ced}$ intensity are the result of gamma rays interacting with attenuat. $\mathrm{g}$ naterial before they reach the detector. See for example the thin ring 1 . he ce atre of the front scan, a consequence of scattering in the walls of the rrvosta endcap, and bands of reduced intensity in the side scan, caused by the matc : al used to physically support the crystal.

Also indicated on Fig. ar the interaction locations for the example signals that will be discussed in ${ }^{\Upsilon} \curvearrowright$. 5 . ?oints $\mathrm{R} 1$ to $\mathrm{R} 4$ lie on a radial line relatively close to the $\mathrm{p}+$ electr de $\mathrm{t} \mathrm{z}=13.5 \mathrm{~mm}$. Points D1 to D4 lie at a fixed radial position on a line throu $h \mathrm{tr} \_$depth of the detector and parallel to the $z$ axis.

\section{Coincider Scan Results}

In the oinc. 'once measurement the first parameter to be studied was the time diff ren e be'ween the signals measured in the SAGe and BGO detectors. The left side $f$ Fig. 8 shows the time difference between triggers generated in the 1 oth det stors during the coincidence scan for all $x$ and $y$ at each $z$ positions, $t^{2}$ - blacn une shows all events generating a trigger and the coloured lines show he ever is selected for mean signal formation at each value of $z$. On the right side ume difference for two BGOs triggered by coincident $511 \mathrm{keV}$ gamma rays f om a ${ }^{22} \mathrm{Na}$ source is shown, this distribution has a FWHM of $23 \pm 2$ ns.

The BGO detectors generated consistent signal shapes which were not de- 


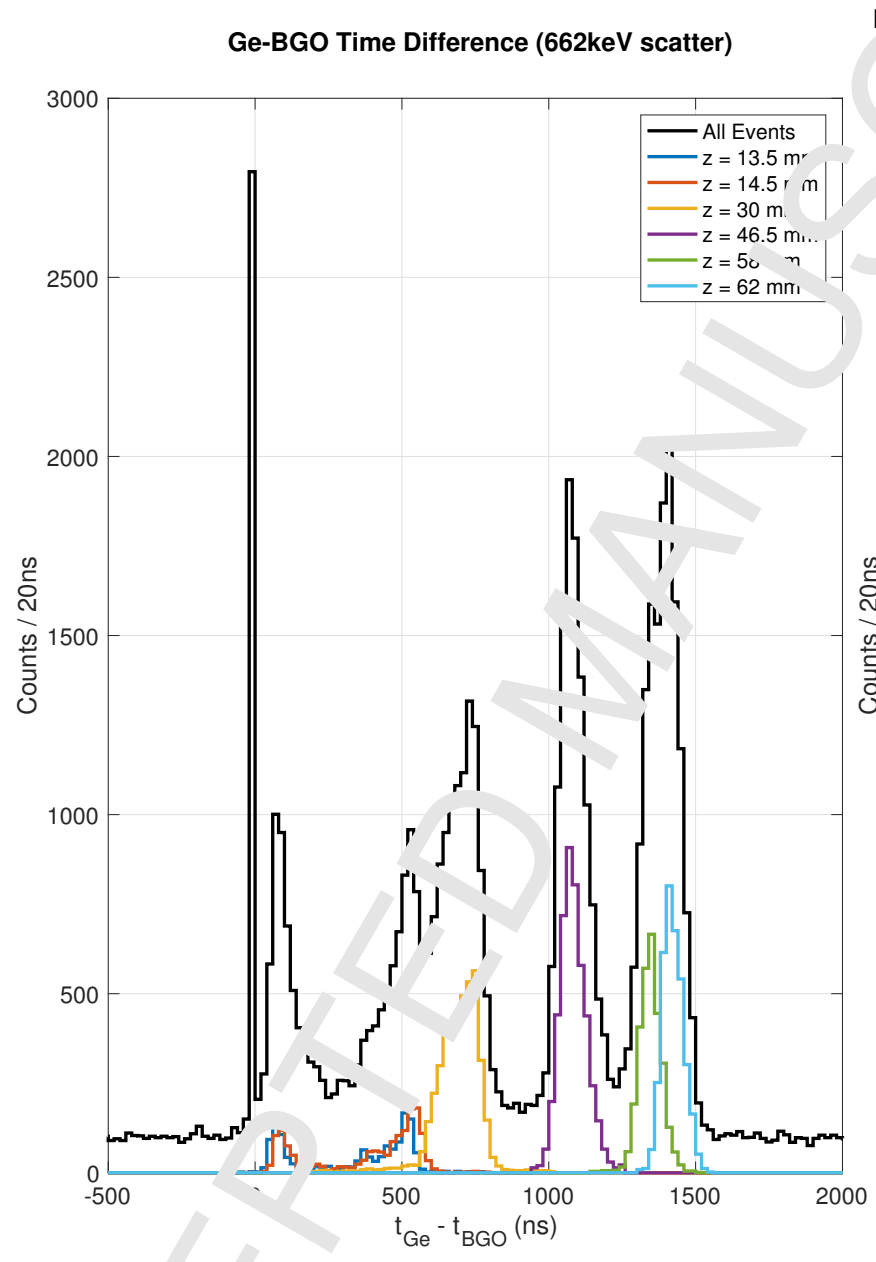

BGO-Bน - Time Difference

(511keV coincidence)

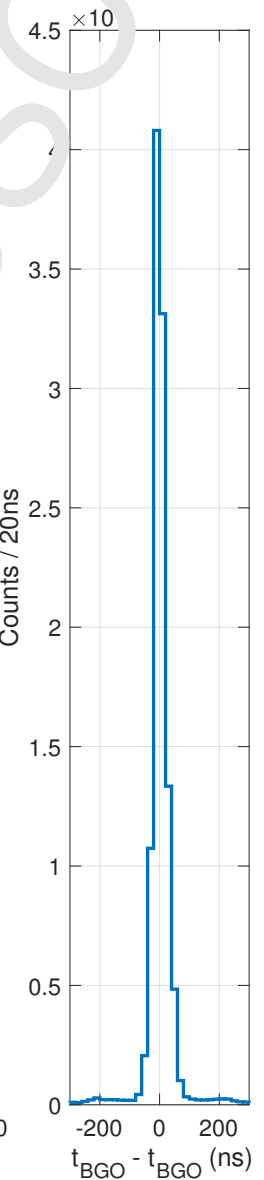

Figu: 8: Histe rrams of the SAGe-BGO time difference obtained during the coincidence scan (left). The $\mathrm{r}$ ack line represents all events generating a coincidence trigger, the coloured nes rer esent signals passing all gates and being used to form mean signals. The BGO'GO tim ng response to $511 \mathrm{keV}$ anhilalation photons from a ${ }^{22} \mathrm{Na}$ source is provided for comparison (right), the FWHM of this distribution was 23ns. 
pendent on the position of interaction. We therefore assume any riatı $\mathrm{I}$ in the SAGE-BGO trigger time difference greater than the BGO $r$ sol $1^{\text {tion }}$ to be due to variation in the SAGe response. This distribution revean + 1e large range of charge collection times observed in the SAGe detector, ith to al collection time increasing with increasing distance from the $\mathrm{p}+$ electrc 'o up t $\mathrm{J}$ a maximum of $1.6 \mu s$ for events near to the detector front face.

The signals in the SAGe detector will now he inves ${ }^{+}$gated for a range of different positions within the detector. For each me in signal formed Fig. 9 shows the rise time for the initial (left) a. I firc' 'entre) parts of the pulse ( $2 \%$ to $30 \%$ and $30 \%$ to $98 \%$ of its heimht m... ctively). Also shown is the mean Ge-BGO trigger time difference for eve. ${ }^{+} \mathrm{s}$ contributing to a mean signal (right), as a function of the position of ' $\eta t$ raction. The $\mathrm{x}$ axis shows the radius of the interaction position and the ', ' ' $\mathrm{z}$ position.

The rise time of the initial pas of the rising edge shows little variation through most of the detect $1 \mathrm{v}$ 'יme as shown by the clustering of events around $400 \mathrm{~ns}$. However there is a trong lependence on radius for events occurring at $\mathrm{z}$ positions closer to the $\mathrm{p}+$ lectrode, with shorter rise times seen at smaller radii. The final part of the 1. 'ng dge again shows little variation through most of the detector voly in hut has a slight dependence on $\mathrm{z}$ for events close to the $\mathrm{p}+$ electrode. The ${ }^{\wedge}$ Ge-BGO time differences on the other hand reveal a strong dependence $\cap z$ of the time before a trigger signal is generated by the SAGe detector.

These " ca s spport the simulated charge collection behaviour described in Sec. ¿, hole produced by a gamma-ray interaction will drift a long way through the a +ector oefore inducing any significant signal on the collecting electrode.

The mean signals produced by the method described in Sec. 3 are aligned 1. 'ative io the SAGe detector trigger time, in order to reveal the true variation in c. me collection time it is necessary to shift them according to the mean SAGe BGO time differences of the contributing signals. This method produces mean signals with the correct shape and timing relative to the BGO signal as shown 

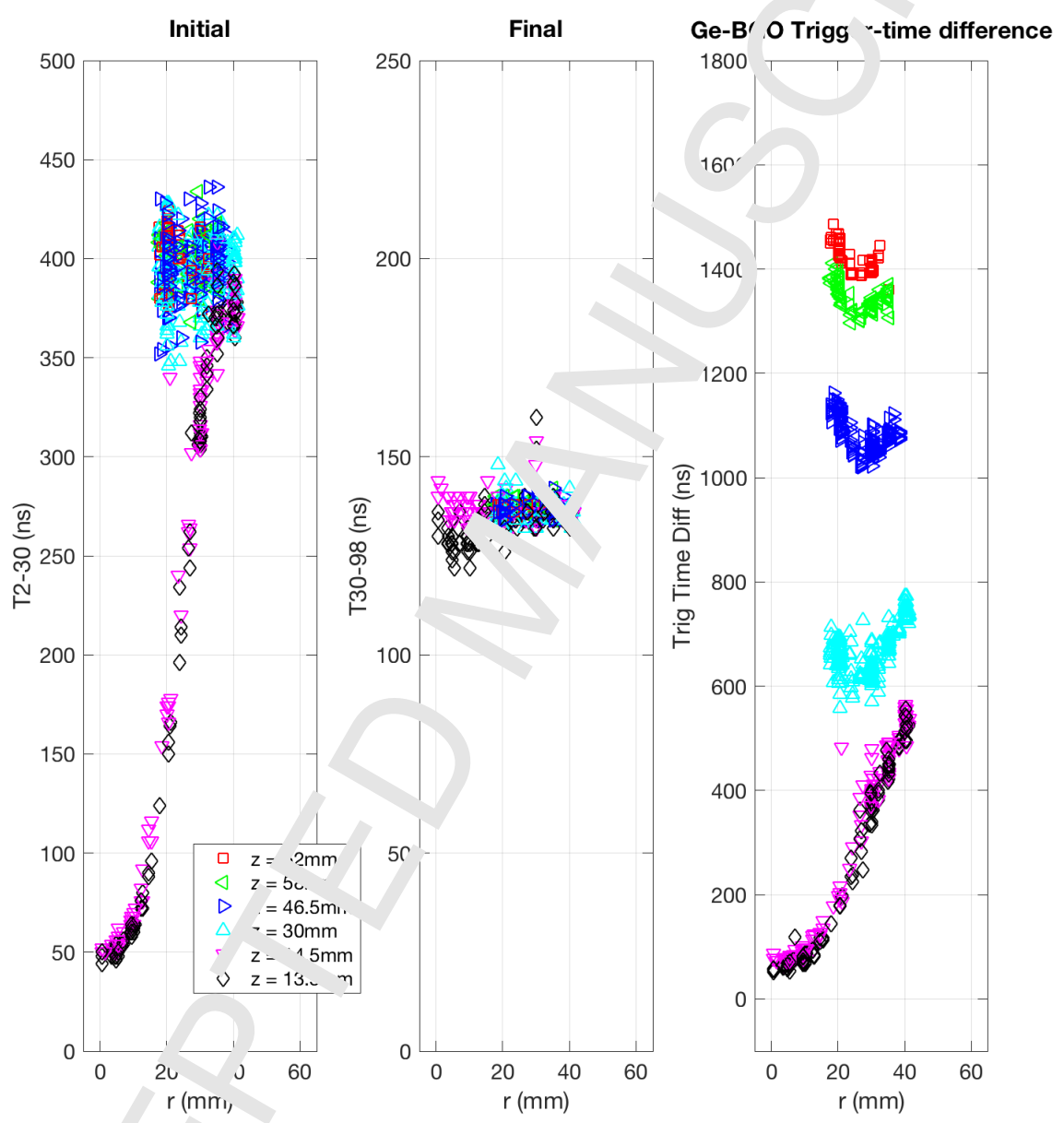

Figu: 9: Shat parameters for signals induced in SAGE detector as a function of position. Time 14 mer signals to go from $2 \%$ to $30 \%$ of their height (left), from $30 \%$ to $98 \%$ of their aight ( ntre), and the mean Ge-BGO trigger time difference (right) for events contributing the $\mathrm{m}$ an signal at each position. The $\mathrm{x}$ axis indicates the radial position of each mean signal, the $\mathrm{z}$ position is indicated by the colour and marker type. 


\section{Investigating Parameters of the Simulation}

Fig. 4 shows the experimental mean signals discı ssed in Sec. 5 together with simulated signals for the same positions. The ${ }^{\circ}$....ulatu signals show qualitatively the same behaviour, with fast rising sig ${ }^{1}$ for nteractions close to the $\mathrm{p}+$ electrode and increasing charge drift time an distance from the electrode increases.

The total charge collection times for the sim. ${ }^{-1}$ ated signals are however much shorter than seen in experiment. For ex nple, charge collection for an interaction at point D4 located at $z=6 \ldots$ +akes $1.1 \mu \mathrm{s}$ compared with $1.6 \mu \mathrm{s}$ in experiment. In particular the initial , trt of charge collection, where charge carriers are far from the p+ electroa $a_{1}{ }^{\prime}$ the induced signal is close to zero, is significantly faster in the simula: 7 .

Broadly, the rate of charge collection is determined by the electric field in the detector and the mobilit of cha ge carriers being collected. The electric field at each point in the d tectu. is determined by the detector crystal geometry, the potential at the lect ode, and the internal electric field due to stationary space charge. Det sls of th geometry were checked against the intensity profiles obtained througn sing scanning (see Fig. 7) and while this measurement revealed sligh $\mathrm{ly} \leqslant$ naller dimensions than the specification the discrepancy can be explainnd by he existence of surface dead layers which are not visible in the scan.

Im $\cdots$ rity centrations were quoted by the manufacturer to within $10 \%$ at the : ont anc back of the crystal, a linear gradient along the $z$ axis was assumed b reen vıese points and no radial variation was included in the model. A inear in purity gradient along the $z$ axis results in a uniform field in the bulk of the uetector where the field due to space charge dominates the overall electric s eld. The linear variation of charge collection time as a function of $z$, seen in F.gs 8 and 9 (right) supports the hypothesis of an impurity gradient which is 
approximately linear in $z$. We were not able to determine if there - any v riation in impurity concentration with $x y$, but any such variation $\mathrm{w}$, ula he expected to contribute mainly to the field in the $x y$ plane and would nc herefore explain the rate of charge collection along the $z$ direction.

In order to establish if uncertainties in the impurity meas rements at each end of the crystal could explain the observed char e $\mathrm{co}^{1} \sim$ ion times we ran the simulations again while shifting the front and $\mathrm{k} \sim \mathrm{ck}$ imnw ty concentrations by up to $20 \%$. Fig. 10 shows the results of these simulatı ns for the induced signal from interactions at point D4. While the - is $a^{*}$;nificant change in charge collection time, the maximum effect of $n$ nor $\sim$ ' it is only enough to increase the charge collection time to $1.2 \mu \mathrm{s}$, still $\operatorname{sig}_{1 .}{ }^{\mathrm{G}}{ }^{\mathrm{c}}$ cantly less than the $1.6 \mu \mathrm{s}$ seen in experiment.

We thus conclude that realistic arta nties in the crystal impurity concentration are not enough to expls: ${ }^{-}$the ' sserved discrepancy in charge collection times.

The hole and electron stu "ity parameters used for the initial simulation were obtained by a fit to - nerim ntal data from the MINIBALL array of coaxial HPGe detectors, d scri’ ${ }^{\prime}$ ed in Ref [8]. These values have had success in simulating the signal $\mathrm{s}^{\wedge}$ ape oren rated in coaxial HPGe detectors from the AGATA array [10]. Whil c c'ernative parametrisations of charge carrier mobility have produced diffe ${ }^{\cdot}{ }^{-}$values [11], comparisons with data from coaxial HPGe detectors have sh. vn elatively little sensitivity of simulation performance to choice mobility ' arameteı $[12,13]$.

Ref $1 \mathrm{O}^{\prime}$ ' oes ot give the temperature of the HPGe crystals when the study was erform od but the liquid-nitrogen-cooled MINIBALL and AGATA crystals typice "lv var f between temperatures of $95 \mathrm{~K}$ and $100 \mathrm{~K}$ under normal conditions 14]. T. o temperature of the SAGe crystal in this study was $113 \mathrm{~K}$, a value which w a chr sen in manufacture to optimise energy resolution. Since this difference If ... ttively large, and the temperature dependence of mobility is stronger in reaker electric fields, a significant temperature correction will be required here.

In order to establish if the longer charge collection times seen in experiment 


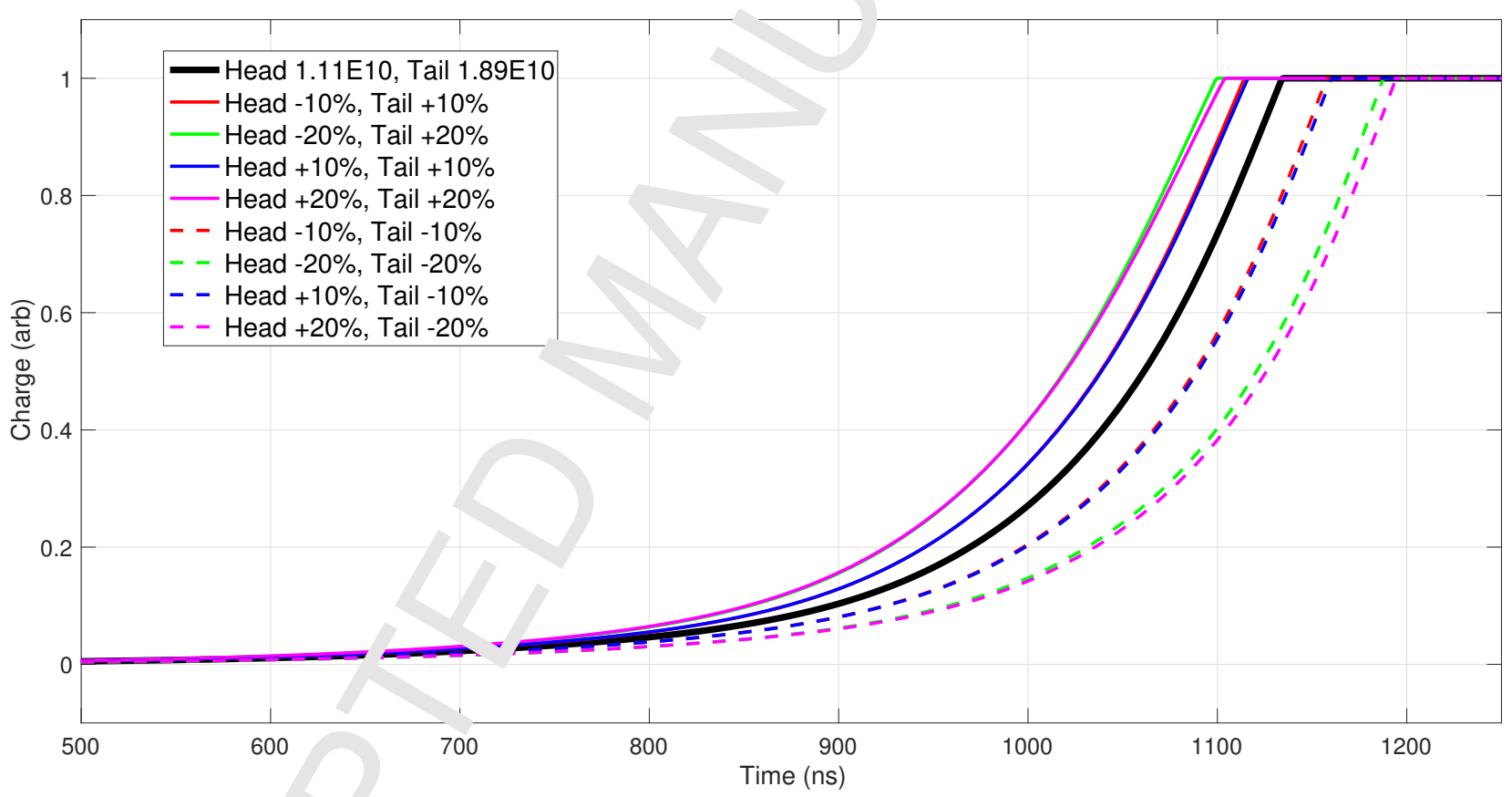

Figure 10 Sim later signals from point D4 using a range of values for the impurity concentration at the ar (front) and tail (back) of the detector. 
could be due to this temperature difference we ran a series of s.- 'ılatı is with adjusted mobility parameters. As the charge collection tim in the SAGe Well is dominated by the hole mobility these signals show little st. ${ }^{*}$ 'ivity to electron mobility. As such we focussed this study on hole mobil' vies on'v. 'The difference between experiment and simulation was most pronoun 'd for nteraction positions with the longest drift distances so we used e iclus . 'v point D4, near the front face of the detector, for this comparison.

Studies on the relationship between mobility and te nperature for germanium found a dependence on $T^{-1.6}$ for electrons and ${ }^{-\top}-9$ for holes $[15,16]$. This dependence equates to a reduction in holn mas: $y$ of $33 \%$ when temperature increases from $95 \mathrm{~K}$ to $113 \mathrm{~K}$.

Fig. 11 shows the simulated sign. 's where the hole mobilities along the $<100>$ and $<111>$ axes were botı $<$. 9 ng 1 by between $+10 \%$ and $-35 \%$. The simulated signal with $-30 \%$ hol - mobi. 'ty provides a good match to experiment for both the total charge collection : ${ }^{\prime}(\approx 1.6 \mu \mathrm{s})$ and the time for the signal to reach $10 \%$ of its height $\sim 1$ us). It is therefore reasonable to conclude that the crystal temperature $u_{\text {. }}{ }^{\mathrm{P}}$ erenc $;$ are the dominant factor in the longer charge collection times seen $\mathrm{n} \mathrm{t}^{\prime}$ is $\mathrm{S}_{\mathrm{H}} \mathrm{Ge}$ well detector. With suitable temperature corrections there i ex. Ilen agreement between simulated signals and those observed in this $t$. intor.

This under" 's the importance of temperature corrections to mobility for accurate sin. 'at: $\mathrm{n}$ of signal shapes, a point which is likely of increased importance giv' $\mathrm{a}$ the pruiferation of inverted-coaxial type detectors with relatively weak fiem 17, 8]. Furthermore, the increasing popularity of mechanically coolf 1 dete tors which may be expected to have a wider range of crystal temperat res th in liquid nitrogen cooled devices, will also increase the importance ,f such orrections. 


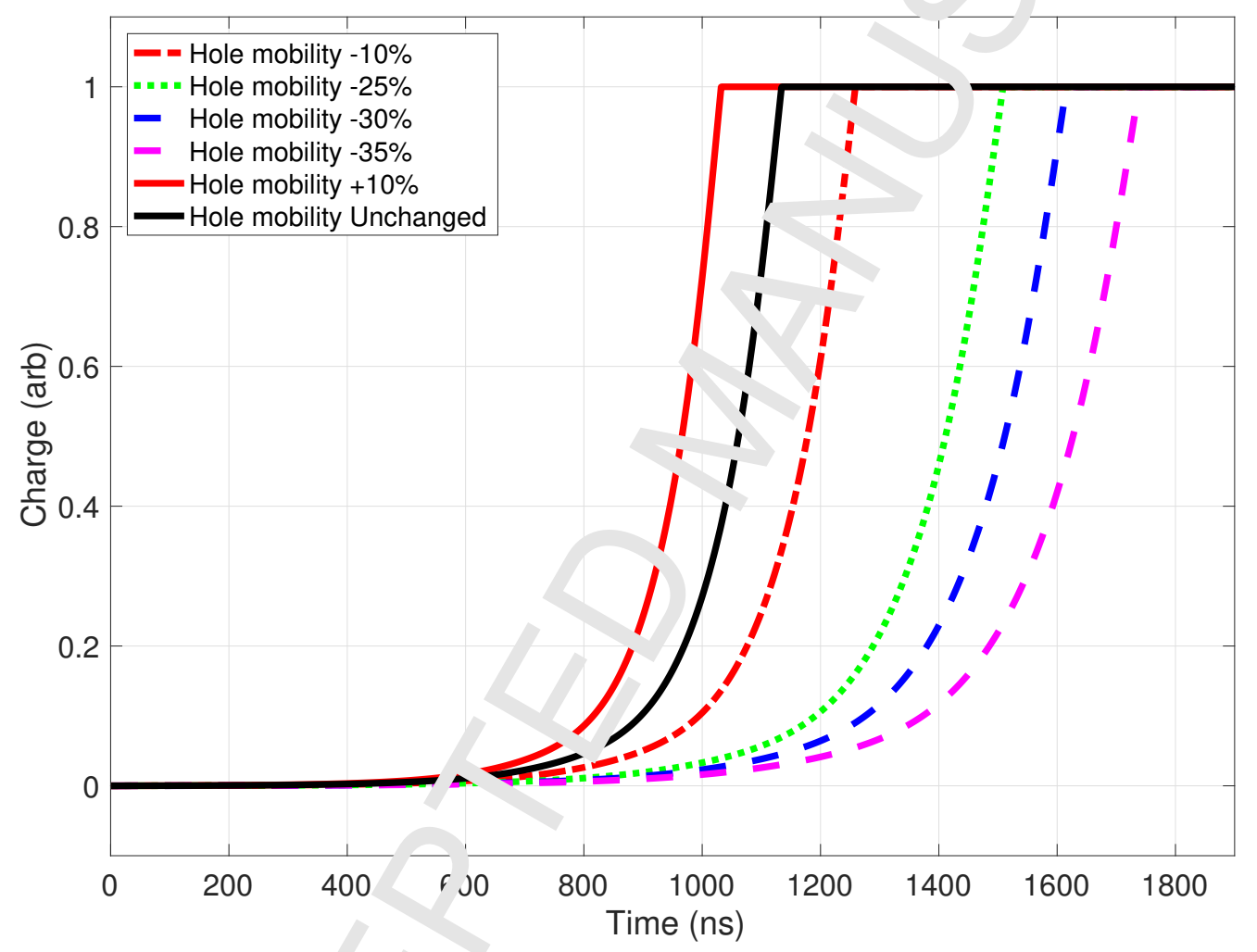

Figure ${ }^{11}$. Sirı ' ied signals from point D4 using a range of values for the detector hole mobi ty in th $<100>$ and $<111>$ direction. The $-30 \%$ shift is equivalent to that expected from a ${ }^{\mathrm{T}-2.3}$ elationship as temperature rises from $97.5 \mathrm{~K}$ to $113 \mathrm{~K}$. 


\section{Acknowledgements}

This research was supported by the United Kingdom Sc; nce $₫$ na Iechnology Facilities Council (STFC UK) grant ST/N003543/1.

55] B. 'ruyneel, P. Reiter, G. Pascovici, Characterization of large volume hpge detectors. part i: Electron and hole mobility parameterization, Nuclear Instruments and Methods in Physics Research Section A: Accelerators, Spectrometers, Detectors and Associated Equipment 569 (3) (2006) 764 - 
773. doi:http://dx.doi.org/10.1016/j.nima.2006.08. . 20.

[6] W. Shockley, Currents to conductors induced bs a mov. ig point charge (1938), Journal of Applied Physics 9 (635). do = htt . . , dx.doi.org/10. 1063/1.1710367.

[7] S. Ramo, Currents induced by electron motion 1939 ), Proceedings of the Institute of Radio Engineers.

[8] B. Bruyneel, P. Reiter, G. Pasco \&, vraı acterization of large volume hpge detectors. part ii: Exporimenta results, Nuclear Instruments and Methods in Physics Researc jection A: Accelerators, Spectrometers, Detectors and Associar ‘ Fquipment 569 (3) (2006) 774 - 789. doi:http://dx.doi.org, ,.1n1, /j.nima.2006.08.129.

URL http://www.sciuncedirect.com/science/article/pii/ S0168900206015178

[9] M. R. Dimmock. A. J. `ston, J. R. Cresswell, I. Lazarus, P. Medina, P. Nolan, C. P. -ise, C. Jantos, J. Simpson, C. Unsworth, Validation of Pulse Shape imulatıus for an AGATA Prototype Detector, IEEE Transactions on Nuclea Science 56. doi:10.1109/TNS.2009.2021842.

[10] S. Akke "n A. Algora, B. Alikhani, F. Ameil, G. de Angelis, L. Arnold, A. A tier A. sta, Y. Aubert, C. Aufranc, A. Austin, S. Aydin, F. Azaiez, 360 S. L. Jer, D. Balabanski, D. Barrientos, G. Baulieu, R. Baumann, J. Bar 'acco, F. Beck, T. Beck, P. Bednarczyk, M. Bellato, M. Bentley, ( Ben oni, R. Berthier, L. Berti, R. Beunard, G. L. Bianco, B. Birkenbâ h, P. Bizzeti, A. Bizzeti-Sona, F. L. Blanc, J. Blasco, N. Blasi, D Bloor, C. Boiano, M. Borsato, D. Bortolato, A. Boston, H. Boston, ?. Bourgault, P. Boutachkov, A. Bouty, A. Bracco, S. Brambilla, I. Brawn, A. Brondi, S. Broussard, B. Bruyneel, D. Bucurescu, I. Burrows, A. Brger, S. Cabaret, B. Cahan, E. Calore, F. Camera, A. Capsoni, F. Carri, 


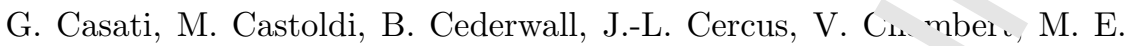
Chambit, R. Chapman, L. Charles, J. Chavas, E. C me ${ }^{+}$P. Cocconi,

'A. Nicoletto, R. Nicolini, Y. L. Noa, P. Nolan, M. Norman, J. Nyberg, A. Obertelli, A. Olariu, R. Orlandi, D. Oxley, C. zben, M. Ozille, C. Oziol, E. Pachoud, M. Palacz, J. Palin, J. Pancin, C. Parisel, P. Pariset, G. Pas- 
covici, R. Peghin, L. Pellegri, A. Perego, S. Perrier, M. Pt. '1, ト. ?etkov, C. Petrache, E. Pierre, N. Pietralla, S. Pietri, M. Pig ant 'li I. Piqueras, Z. Podolyak, P. L. Pouhalec, J. Pouthas, D. Pugnre, V. ‥ snell, A. Pullia, B. Quintana, R. Raine, G. Rainovski, L. Ramir ı, G. Pampazzo, G. L. Rana, M. Rebeschini, F. Recchia, N. Redon, M. Re `e, P. ieiter, P. Regan,

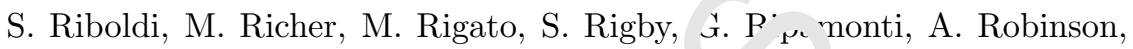
J. Robin, J. Roccaz, J.-A. Ropert, B. R ^ss, C P. Alvarez, D. Rosso, B. Rubio, D. Rudolph, F. Saillant, E. ahin, F. Salomon, M.-D. Salsac, J. Salt, G. Salvato, J. Sampson, E. Sanc:- C. Santos, H. Schaffner, M. Schlarb, D. Scraggs, D. Seddon, м …; , M.-H. Sigward, G. Simpson, J. Simpson, M. Slee, J. Smith, P. Sona, ? Sowicki, P. Spolaore, C. Stahl, T. Stanios, E. Stefanova, O. St 'w ki, J. Strachan, G. Suliman, P.-A. Sderstrm, J. Tain, S. Tangu. S. ' s shenov, C. Theisen, J. Thornhill, F. Tomasi, N. Toniolo, P Touz ry, B. Travers, A. Triossi, M. Tripon, K. Tun-Lano, M. Turcato, C. U. worth, C. Ur, J. Valiente-Dobon, V. Vandone, E. Vardaci, R ven 'relli, F. Veronese, C. Veyssiere, E. Viscione, R. Wadsworth, P. v'lker, 7. Warr, C. Weber, D. Weisshaar, D. Wells, O. Wieland, A. ' vier, G. Wittwer, H. Wollersheim, F. Zocca, N. Zamfir, M. Ziebliski, A. 'Zu hia ri, Agataadvanced gamma tracking array, Nuclear Instruments a d Methods in Physics Research Section A: Accelerators, Spectrom'- 's, Detectors and Associated Equipment 668 (2012) 26 - 58. doi:ht..s: /doi.org/10.1016/j.nima.2011.11.081.

URI http://www.sciencedirect.com/science/article/pii/ S016?, 021.021516

[11] [. Mih ilescu, W. Gast, R. Lieder, H. Brands, H. Jger, The influc... of anisotropic electron drift velocity on the signal shapes of slosed-end $\{\mathrm{HPGe}\}$ detectors, Nuclear Instruments and Methuus in Physics Research Section A: Accelerators, Spectrometers, Detectors and Associated Equipment 447 (3) (2000) 350 - 360. doi:http://dx.doi.org/10.1016/S0168-9002(99)01286-3. 
URL http://www.sciencedirect.com/science, rtic_ə/pii/

[12] M. Schlarb, R. Gernhuser, S. Klupp, R. Krcken, Pulse sı 'ne analysis for -ray tracking (part i): Pulse shape simulation w: h jass, Đur. Phys. J. A 47 (10) (2011) 132. doi:10.1140/epja/i2011-111ui?

URL https://doi.org/10.1140/epja/i201-1.13i-2

[13] V. Prasher, M. Cromaz, E. Merchan, P. Thowdhury, H. Crawford, C. Lister, C. Campbell, I. Lee, A. Macc ' `vell;, D. Radford, A. Wiens, Sensitivity of gretina position resolution ר hole mobility, Nuclear Instruments and Methods in Physics ?esearch Section A: Accelerators, Spectrometers, Detectors and A soc» Equipment 846 (2017) 50 - 55. doi:https://doi.org/10.1\% h/j.. ima.2016.11.038.

URL http://www.sci.ncedirect.com/science/article/pii/ S0168900216311925

[14] H. Hess, Private com .um ation (2018).

[15] R. Lawrance, The +emp rat re dependence of drift mobility in germanium, Phys. Rev. 89 (`953'129־-1295. doi:10.1103/PhysRev.89.1295.

URL https://link. 's.org/doi/10.1103/PhysRev.89.1295

[16] M. B. Prince, Dritu nobilities in semiconductors. i. germanium, Phys. Rev. 92 (195:, 68 -687. doi:10.1103/PhysRev.92.681.

URL tttps.'/link.aps.org/doi/10.1103/PhysRev.92.681

450 [17] J. v : ht, L. Harkness-Brennan, A. Boston, D. Judson, M. Labiche, Nol , R. Page, F. Pearce, D. Radford, J. Simpson, C. Unsworth, Poition $r$ solution simulations for the inverted-coaxial germanium detector, sic na, Nuclear Instruments and Methods in Physics Research Section A: Ar elerators, Spectrometers, Detectors and Associated Equipment 892 '2018) 84 - 92. doi:https://doi.org/10.1016/j.nima.2018.02.106.

URL http://www.sciencedirect.com/science/article/pii/ S0168900218302948 
[18] A. Domula, M. Hult, Y. Kermadic, G. Marissens, B. D'rwing .heuer, T. Wester, K. Zuber, Pulse shape discrimination perfr $m_{\dot{c}}$ nee of inverted coaxial ge detectors, Nuclear Instruments and Meth 1 in Physics Research Section A: Accelerators, Spectrometers, $\Gamma$ stector and Associated Equipmentdoi:https://doi.org/10.1016/j.nim 201s.02.056.

URL http://www.sciencedirect. :om/ u ence/article/pii/ S0168900218302122 